\title{
Bacterial ghosts as adjuvants in syngeneic tumour cell lysate-based anticancer vaccination in a murine lung carcinoma model
}

\author{
JAN ALEKSANDER KRAŚKO ${ }^{1-3}$, KAROLINA ŽILIONYTE் $^{1}$, ADAS DARINSKAS ${ }^{1,3,4}$, MARIUS STRIOGA ${ }^{1}$, \\ SVETLANA RJABCEVA $^{5}$, IOSIF ZALUTSKY ${ }^{5}$, MARINA DEREVYANKO ${ }^{5}$, VLADIMIR KULCHITSKY ${ }^{5}$, \\ WERNER LUBITZ $^{6}$, PAVOL KUDELA $^{6}$, EDITA MISEIKYTE-KAUBRIENE ${ }^{1}$, OLHA KARAMAN $^{7}$, \\ HENNADII DIDENKO $^{7}$, HRYHORII POTEBNYA $^{7}$, VASYL CHEKHUN ${ }^{7}$ and VITA PAŠUKONIENE ${ }^{1}$ \\ ${ }^{1}$ National Cancer Institute, LT-08660 Vilnius; ${ }^{2}$ State Research Institute Centre for Innovative Medicine, LT-08406 Vilnius; \\ ${ }^{3}$ JSC ‘Froceth', LT-08217 Vilnius; ${ }^{4}$ JSC ‘Innovita Research', LT-06118 Vilnius, Lithuania; \\ ${ }^{5}$ Institute of Physiology, BY-220072 Minsk, Republic of Belarus; ${ }^{6}$ BIRD-C GmbH, A-1030 Vienna, Austria; \\ ${ }^{7}$ R.E. Kavetsky Institute of Experimental Pathology, Oncology and Radiobiology, NAS of Ukraine, 03022 Kyiv, Ukraine
}

Received May 20, 2016; Accepted July 22, 2016

DOI: $10.3892 /$ or.2016.5252

\begin{abstract}
Instead of relying on external anticancer factors for treatment, immunotherapy utilizes the host's own immune system and directs it against given tumour antigens. This study demonstrated that it is possible to overcome the documented immunosuppressive properties of tumour cell lysate by supplementing it with appropriate adjuvant. Lewis lung carcinoma (LLC)-challenged C57BL/6 mice were treated with LLC cryo-lysate mixed with either bacterial ghosts (BGs) generated from E. coli Nissle 1917 or B. subtilis $70 \mathrm{kDa}$ protein as adjuvants. Median and overall survival, the size of metastatic foci in lung tissue and levels of circulating CD8 $\mathrm{a}^{+} \mathrm{T}$ cells were evaluated and compared to the untreated control mice or mice treated with LLC lysate alone. After primary tumour removal, a course of three subcutaneous vaccinations with LLC lysate supplemented with BGs led to a significant increase in overall survival ( $80 \%$ after 84 days of follow-up vs. $40 \%$ in untreated control mice), a significant increase in circulating $\mathrm{CD} \mathrm{a}^{+}$ $\mathrm{T}$ cells (16.57 vs. $12.6 \%$ in untreated control mice) and a significant decrease in metastasis foci area and incidence. LLC lysate supplemented with $B$. subtilis protein also improved the inspected parameters in the treated mice, when compared against the untreated control mice, but not to a significant degree. Therefore, whole cell lysate supplemented with BGs emerges as an immunostimulatory construct with potential clinical applications in cancer treatment.
\end{abstract}

Correspondence to: Jan Aleksander Kraśko, National Cancer Institute, Santariškių 1, LT-08660 Vilnius, Lithuania

E-mail: krasko.jan@gmail.com

Key words: bacterial ghosts, Bacillus subtilis, anticancer vaccination, adjuvant, mice, Lewis lung carcinoma, metastasis

\section{Introduction}

The immune system plays a critical role in the prevention of tumour development. The sophisticated bidirectional interaction between cancer cells and the immune system is defined as cancer immunoediting (1). Unfortunately, during this dynamic process, malignant cells may acquire various molecular and cellular mechanisms enabling them to escape immune-mediated control and manifest as clinically apparent cancer. Various immune evasion mechanisms can be grouped into immunoselection (antigen loss on cancer cell surface) and immunosubversion (tumour-driven active creation of local and systemic immunosuppressive milieu) (2). Due to impaired and disbalanced antitumour immunity in cancer patients $(3,4)$, immune response-modulating strategies, known as tumour immunotherapy, have been introduced into clinical practice. Among the various types of cancer immunotherapy (5), therapeutic cancer vaccination is one of the most promising approaches, especially when combined with other immunotherapeutic strategies as well as cancer chemotherapy, radiation therapy and targeted therapies (6).

Therapeutic cancer vaccination aims at inducing and/or augmenting cytotoxic cellular immune responses that are able to quantitatively and qualitatively overwhelm the cancer-driven immunosuppressive arm of antitumour immune response (7). Therapeutic vaccines exploit mostly dendritic cells (DCs) that are the main initiators and orchestrators of adaptive immune responses (8). DCs can be targeted either in situ or generated ex vivo and reinjected back into the same patient to achieve their therapeutic effect. Selection of proper tumour-associated antigens (TAAs) and induction of optimal DC maturation are the critical steps in therapeutic cancer vaccination (9). Based on antigen selection strategy, therapeutic vaccines can be mono- or oligovalent (using one or several defined TAAs) and polyvalent (a variety of undefined TAAs is used). In theory, polyvalent vaccines should be superior to mono- or oligovalent vaccines, since the former mobilize the immune system to target more than just one or few TAA(s), which could be 
potentially lost in individual cases (10). Moreover, tumours are known to be heterogeneous (11); therefore targeting one antigen may target only a portion of the whole tumour cell spectrum.

Tumour cell lysate (TCL) contains a mixture of proteins resulting from induced lysis of tumour cells, which ensures a broad spectrum of target antigens (12). Furthermore, the TCL approach to vaccination does not require $a$ priori knowledge of relevant TAAs and targets also potentially unknown TAAs (13). The ease of manufacturing and storage, lack of limitations dictated by host-specificity and no obligation to know specific TAAs make TCL an appealing vaccine candidate. On the other hand, TCL contains not only immunogenic TAAs, but also various immunosuppressants naturally occurring in cancer cells, such as hyaluronan, known for inducing tolerogenic rather than immunogenic maturation of DCs and macrophages (14). Agents, such as Fas ligand (15) or transforming growth factor- $\beta$ (16), inducing the apoptosis of immune cells are also thought to be present in TCL (17). However, the negative effects of immunosuppressive components present within TCL may potentially be compensated by properly selected immunostimulatory adjuvants that are otherwise used for the induction of DC maturation (9).

Adjuvants used in therapeutic cancer vaccination include Toll-like receptor (TLR) agonists [e.g. imiquimod, resiquimod and lypopolysaccharide (LPS)], cytokines (e.g. granulocyte-macrophage colony-stimulating factor, interferons and interleukins), prostaglandin $\mathrm{E}_{2}$ and their combinations (18). It was demonstrated that proper combinations of various TLR agonists are needed for adequate induction of DC maturation (19). Hence the use of natural sources of multiple adjuvants may optimize therapeutic cancer vaccination strategies. Indeed, it was demonstrated that parts of, or whole, inactivated, pathogens have a positive impact on the effectiveness of the TCL-derived vaccines. Experiments on animals and human trials were performed with viral particles per se (20), but also as an antigen delivery system, i.e. virosomes. Virosomes are spherical nanoparticles consisting of a non-viral component: a phospholipid bilayer, with an embedded viral component on the surface: influenza virus hemagglutinin and neuraminidase are the most popular choice. The viral components enable virosomes to fuse with antigen presenting cells (APCs) and release their contents directly into the APC cytoplasm, triggering immune response against the antigen in question (21). Virosomes also possess immunostimulatory properties on their own (22), and virosomal vaccines are capable of eliciting both $\mathrm{T}_{\mathrm{h}}$ and CTL responses (23). Their efficacy has been demonstrated in many animal models (24) and in clinical trials, e.g. where virosomal vaccine containing Her $2 /$ neu peptides induced specific antibody production and a decrease in circulating regulatory T-lymphocytes in metastatic breast cancer patients (25).

A possible downside to virosomes is the fact that, due to the presence of only selected viral proteins, they only have a fraction of viral full immunostimulatory potential. The rather limited capacity of a single virosome is also considered a drawback. In this regard, bacterial ghosts (BGs), empty and intact non-living bacterial cell envelopes, comprise a platform that can serve both as a source of multiple adjuvants and a system for antigen delivery to DCs. BGs are generated by controlled expression of bacteriophage-cloned protein E-inducing lysis of Gram-negative bacteria $(26,27)$. The product of E protein-specific lysis is the intact shell of the bacteria with a conserved surface and periplasmic molecules that serve as danger signals and immune potentiators $(26,28,29)$ and an empty inside, which can be loaded with the desired antigens. Such a construct is ready to use as a compound delivery system (30), an anti-bacterial vaccine on its own $(31,32)$ or a system for the induction of DC maturation and loading them with antigens, such as TAAs, in a single-step process (33). BGs represent a novel approach towards vaccination, immunomodulation and drug delivery boasting various product advantages. They are stable at room temperature (RT), non-living and carry almost no residual DNA. Having the external immunological properties of living bacteria, BGs act as a natural adjuvant (34).

Bacillus subtilis (B. subtilis) is known to have anticancer properties, both on its own, as well as its metabolites. B. subtilis protein metabolites retrieved from culture medium filtrate have been described as lectins (35) and have been investigated as potential anticancer agents due to their cytotoxic properties (36). Their application as adjuvant has been first tested in a murine sarcoma model, in combination with probiotics $(36,37)$, interferon- $\gamma$ (38) or on its own (39), where tumour growth inhibition, survival benefit, as well as stimulation of macrophages and spleen mononuclear cells were reported. Lewis lung carcinoma (LLC) model in C57BL/6 mice was also used with promising results, regarding tumour inhibition index $(40,41)$, activity of antitumor effector cells (40-42) and mouse survival $(41,42)$. B. subtilis is also known to have immunostimulatory properties on DCs; both on its own (43), as well as its metabolites (44).

In the present study, we investigated the immunostimulatory potential of E. coli Nissle 1917 BGs (as a source of multiple immune potentiators) and B. subtilis B-7025 $70 \mathrm{kDa}$ (B.s. B-7025) protein isolates as candidate adjuvants for TCL-based therapeutic cancer vaccine in a murine lung cancer model.

\section{Materials and methods}

Mice and cell lines. Eight- to 12-week-old female C57BL/6 mice were obtained from the State Research Institute Centre for Innovative Medicine (Vilnius, Lithuania). Mice were housed in plastic cages (10 mice/cage) under normal daylight conditions with water and food ad libitum. All animal procedures were carried out in accordance with the Directive of the European Parliament and of the Council on the Protection of Animals Used for Scientific Purposes along with approval of the Lithuania State Food and Veterinary Service.

Murine metastatic Lewis lung carcinoma LLC1 (LLC) cell line was a kind gift from R.E. Kavestky Institute of Experimental Pathology, Oncology and Radiobiology (Kyiv, Ukraine). Cells were cultivated in Dulbecco's modified Eagle's medium (DMEM) (Lonza, Verviers, Belgium) containing $2 \mathrm{mM}$ L-glutamine, $10 \%$ foetal bovine serum, $100 \mathrm{U} / \mathrm{ml}$ penicillin and $100 \mu \mathrm{g} / \mathrm{ml}$ streptomycin (both from Gibco, Paisley, $\mathrm{UK}$ ) in humidified atmosphere containing $5 \% \mathrm{CO}_{2}$ at $37^{\circ} \mathrm{C}$. LLC cells were used for tumour implantation and for preparation of autologous tumour lysate. 
Daily mice monitoring, lung samples collection from dead mice

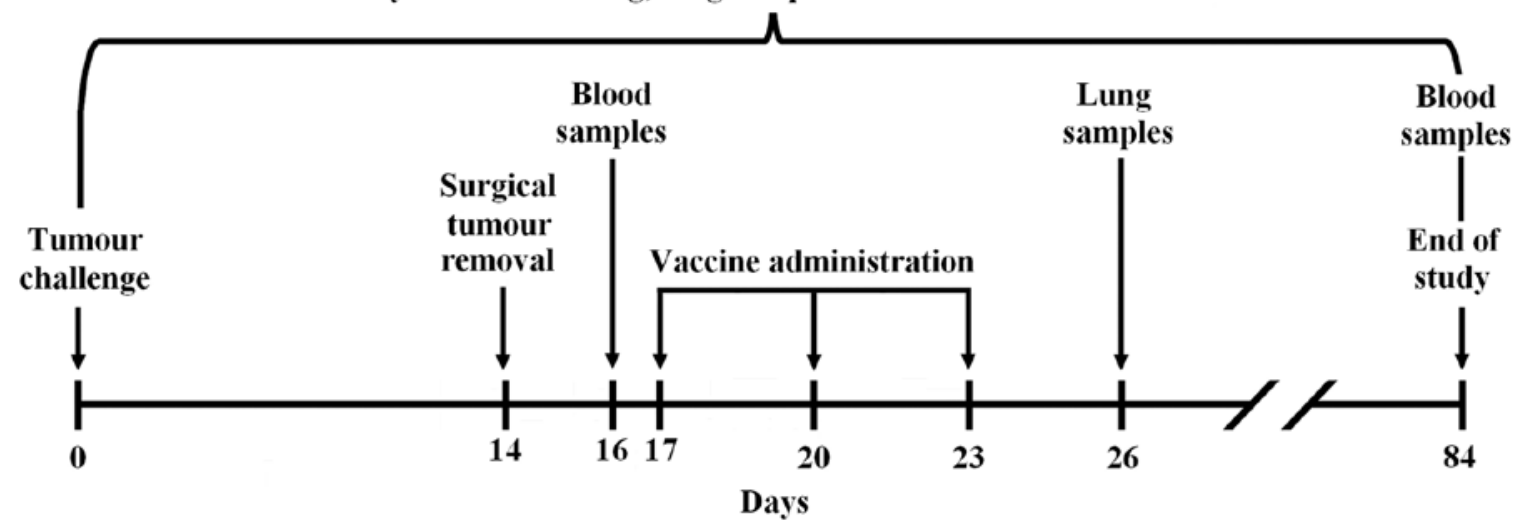

Figure 1. Experimental anticancer vaccination and sampling scheme for C57BL/6 mice challenged with Lewis lung carcinoma (LLC). Experimental design depicted from the time of tumour challenge (day 0 ) until the end of the survival observation (day 84).

$B G$ preparation. Probiotic Gram-negative strain E. coli Nissle 1917 was used for the generation of BGs. BGs were produced by the controlled expression of the phage-derived lysis protein E, as we have described previously (45). Due to the safety reasons, the BG preparation was treated with $\beta$-propiolactone (Ferak, Berlin, Germany) to fully inactivate all residual non-lysed viable bacterial cells and DNA present in BG suspension, followed by extensive washing via tangential flow filtration method (45). Aliquots of washed BGs were frozen at $-80^{\circ} \mathrm{C}$ and lyophilized. Dry-powdered product was stored at RT until further use.

B. subtilis B-7025 protein preparation. The B. subtilis B-7025 protein with molecular mass of $70 \mathrm{kDa}$ was retrieved from culture filtrate on day 10 by protein precipitation with ammonium sulfate (Alpharus NVP, Ukraine), followed by chromatographic separation on a Sephacryl column S-200 (GE Healthcare Bio-Sciences AB, Uppsala, Sweden), as described elsewhere $(46,47)$. Acquired protein mix is not structural bacterial protein, but rather lectin metabolite of B. subtilis B-7025 $(35,37,46,47)$. The protein concentration was determined by the Lowry method (48). The protein metabolite purity was verified by sodium dodecylsulphate polyacrylamide gel electrophoresis. The protein concentrate was sterilised using 0.20- $\mu \mathrm{m}$ filters (Sigma, St. Louis, MO, USA) and stored at $-20^{\circ} \mathrm{C}$.

Preparation of autologous tumour lysate. To prepare autologous tumour lysate, LLC cells were collected via trypsin digestion (Gibco), washed with phosphate-buffered saline (PBS) (Lonza) 3 times and resuspended in $1 \mathrm{ml}$ of PBS. Cells were treated with 6 freeze-thaw lysing cycles using liquid nitrogen and a $37^{\circ} \mathrm{C}$ water bath in an alternating manner. Cells were centrifuged at 4,000 x g for $10 \mathrm{~min}$, and the supernatant was collected and passed through a $0.2-\mu \mathrm{m}$ syringe filter (Corning, Inc., Corning, NY, USA). Protein concentration was determined by the the Lowry method (48). Protein concentration in TCL was $150 \mu \mathrm{g} / 100 \mu \mathrm{l}$ of PBS/dose.

Formulations of therapeutic vaccines. The first vaccine was generated by mixing $150 \mu \mathrm{g}$ of LLC lysate with $0.1 \mathrm{mg}$ ( $2 \times 10^{8}$ particles) of BGs in $100 \mu \mathrm{l}$ of PBS per dose ('LLC+BGs' vaccine). The second vaccine was generated by mixing $150 \mu \mathrm{g}$ of LLC lysate with $150 \mu \mathrm{g}$ of B. subtilis B-7025 $70 \mathrm{kDa}$ protein mix in $100 \mu 1$ of PBS per dose ('LLC+B.s.B-7025' vaccine). The third vaccine consisted of LLC lysate alone, i.e. without adjuvant. Injection of PBS alone served as a negative control (control group).

Tumour challenge and therapeutic vaccination. Mice received a subcutaneous (s.c.) injection of $3 \times 10^{5}$ LLC cells in the left hind-foot on day 0 . On day 14 , primary tumours were surgically removed by amputating the foot. Mice with the primary tumour removed were subsequently treated with either $\mathrm{LLC}+\mathrm{BG}$ vaccine $(\mathrm{n}=13)$, or $\mathrm{LLC}+B . s . \mathrm{B}-7025$ vaccine $(n=13)$, or LLC lysate alone $(n=11)$. Tumour-challenged, but untreated mice $(n=13)$ served as a control group. Mice in the treated groups were vaccinated according to the same scheme; each vaccine was injected s.c. into the nape of the neck on days 17, 20 and 23. See vaccination scheme in Fig. 1. Mice were observed until day 84 .

Sampling. In order to assess the anticancer effectiveness of the vaccines, mouse lung and blood samples were obtained (Fig. 1). Lungs were analysed for metastasis since they are the preferred metastatic location for the LLC cell line (49). Blood samples were collected from the hip vein before vaccination onset (day 16) and from the surviving mice of each experimental group at the end of the experiment (day 84). Three days after the completion of the therapeutic vaccination course (day 26), 3 mice from each group were sacrificed to determine the presence of micrometastases. Mice found dead during the follow-up period underwent histological analysis as well. The survival of mice was observed daily throughout the experiment, with the exception of mice sacrificed on day 26 , which were not taken into account.

Analysis of metastasis. In each case, lung tissue was fixed in $10 \%$ neutral buffered formalin, dehydrated in alcohol baths ( $70 \%$ for $12 \mathrm{~h} / 90 \%$ for $12 \mathrm{~h} / 100 \%$ for $24 \mathrm{~h}$ ) and embedded in paraffin. The formed paraffin blocks were cut with a microtome into slices $3-\mu \mathrm{m}$ thick. The sections were deparaffinised, rehydrated and stained with hematoxylin and eosin morphological stain. Each section was examined with a light 


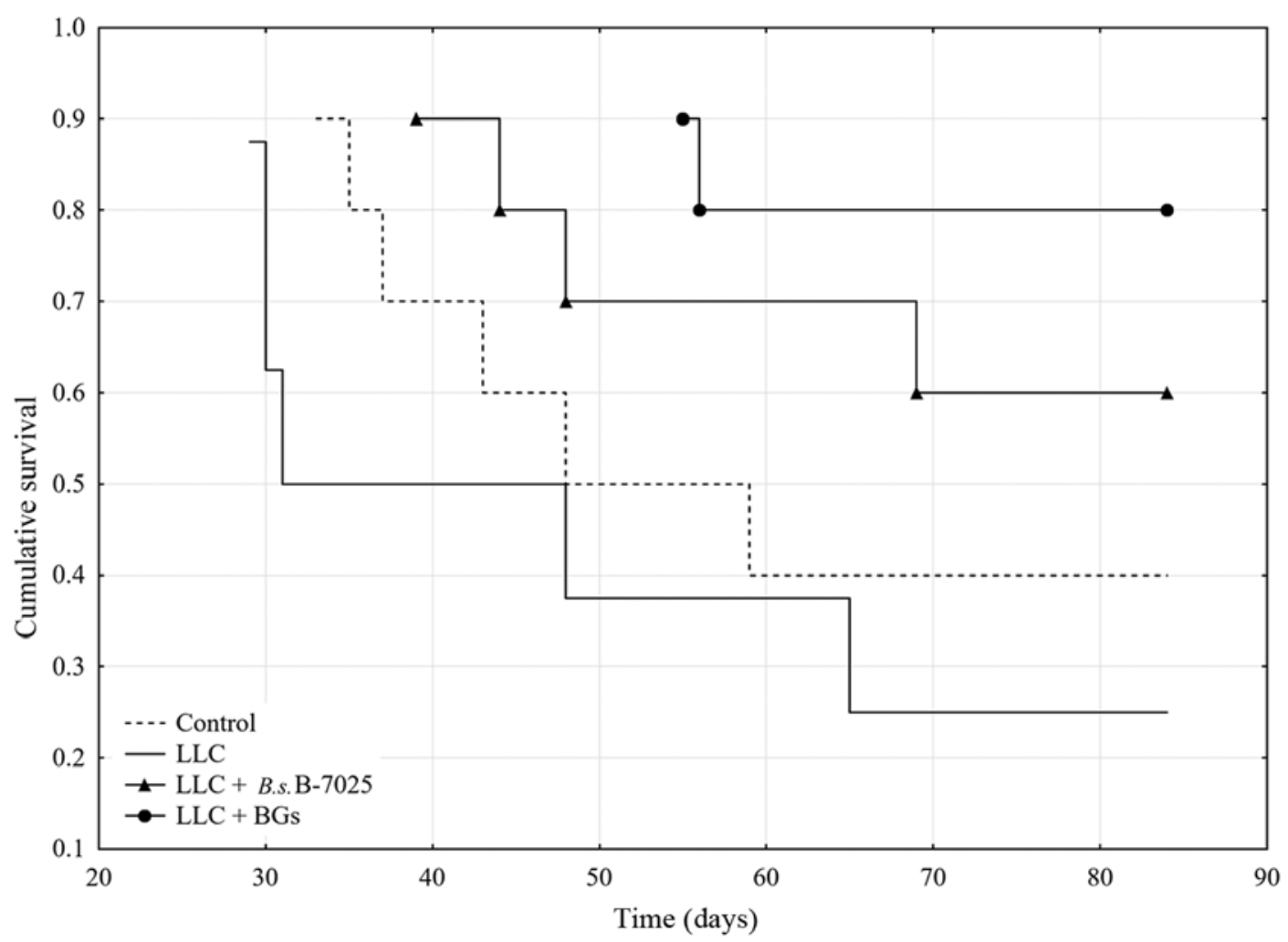

Figure 2. Kaplan-Meier survival curves for C57BL/6 mice undergoing anticancer autologous lysate-based therapeutic vaccination. Control, Lewis lung carcinoma (LLC), LLC+B.s.B-7025 and LLC+BGs groups are plotted from observation day 25 to 84.

microscope in order to identify the tumour-infiltrated areas. Images were captured with an automated Leica DM50000 B microscope equipped with a Leica DFC420 C digital camera (Leica, Wetzlar, Germany). Images were processed using the 'Sharpen' option in the 'ImageJ' image analysis program (50). The area of all tumour nodules that were found in lung tissue was estimated by 'Freehand selection tool' in 'ImageJ', and measurements were expressed in $\mathrm{mm}^{2}$.

Flow cytometry. Blood samples were collected and analysed by flow cytometry for CD8a surface expression at two different time-points (days 26 and 84). One hundred microliters of whole blood was stained with PE-Cy7-conjugated rat anti-mouse CD8a antibody (cat 552877), according to the manufacturer's instructions and lysed with FACS lysing solution (both from BD Pharmingen, San Diego, CA, USA). Samples were acquired with LSR II flow cytometer (BD Pharmingen), using $488 \mathrm{~nm}$ excitation laser and 780/60 band pass filter. At least $1 \times 10^{5}$ cells were analysed with FACSDiva software (BD Pharmingen). Singlets and alive cells were identified based on forward (FSC) and side (SSC) scatter profile.

Statistical analysis. All statistical analyses were performed using Statistica 10 software (StatSoft, Tulsa, OK, USA). Survival was evaluated by Kaplan-Meier method and differences in survival distributions were assessed using ANOVA. Weighted ANOVA variant was used to take into account the differences in the mouse count in the groups. Post-hoc analysis was performed using the Dunnett's test. Differences between tumour areas in lung histochemistry slides were assessed using the Mann-Whitney U-test. Flow cytometry data were analysed with the unpaired, two-tailed Student's t-test. Differences were considered statistically significant for P-values $<0.05$.

\section{Results}

Survival analysis. The differences in the survival between the groups were analysed using several statistical models. Kaplan-Meier survival curves are displayed in Fig. 2. By the end of the observation period (day 84) the survival rate in the LLC+BGs group, LLC+B.s.B-7025 group, LLC group and control group was $80,60,25$ and $40 \%$, respectively.

ANOVA survival analysis $[\mathrm{F}(2,25)=5.0116, \mathrm{P}=0.01478]$ indicated statistically significant differences in survival times between the groups (Table I). Post-hoc analysis showed that mice in the LLC+BGs group, but neither in the LLC+B.s.B-7025 group nor the LLC group, survived significantly longer compared with the untreated control. This indicated that treatment with LLC+B.s.B-7025 and non-adjuvanted LLC lysate had no therapeutic effect in this experimental setting. There was no significant survival difference between mice treated with LLC+BGs and LLC+B.s.B-7025 vaccines, but the group treated with LLC lysate alone had statistically lower survival than the groups treated with LLC+BGs or LLC+B.s.B-7025 vaccines (Table II).

Analysis of metastasis. Three days after the last vaccination, no metastatic foci were found in the sacrificed mice in any of the groups. On the other hand, morphological analysis of the mice that died during the follow-up period revealed 
Table I. Survival of the C57BL/6 mice after removal of LLC tumour and subsequent therapeutic vaccination with various formulations of syngeneic LLC lysate.

\begin{tabular}{lcccccc}
\hline Group & $\begin{array}{c}\text { Days } \\
(\text { median })\end{array}$ & $\begin{array}{c}\text { Days } \\
(\text { mean })\end{array}$ & $\begin{array}{c}\text { Days } \\
\text { (Std.Err. })\end{array}$ & $\begin{array}{c}\text { Days } \\
(-95.00 \%)\end{array}$ & $\begin{array}{c}\text { Days } \\
(+95.00 \%)\end{array}$ & $\begin{array}{c}\mathrm{n} \\
\text { (total=28) }\end{array}$ \\
\hline Control & 53.5 & 59 & 7 & 43 & 75 & 10 \\
LLC & 39.5 & 50 & 9 & 30 & 70 & 8 \\
LLC+B.s.B-7025 & 84.0 & 70 & 6 & 57 & 84 & 10 \\
LLC+BGs & 84.0 & 78 & 4 & 70 & 87 & 10 \\
\hline
\end{tabular}

LLC, Lewis lung carcinoma; BGs, bacterial ghosts; B.s.B-7025, B. subtilis B-7025 $70 \mathrm{kDa}$.

Table II. ANOVA post-hoc analysis of survival (Dunnett's method).

\begin{tabular}{lcccc}
\hline Group & \multicolumn{4}{c}{ P-value } \\
\hline Control & - & 0.3486 & 0.9834 & 0.9989 \\
LLC & 0.9621 & - & 0.9989 & 1.0000 \\
LLC+B.s.B-7025 & 0.2296 & $\mathbf{0 . 0 4 8 5}$ & - & 0.9559 \\
LLC+BGs & $\mathbf{0 . 0 4 7 5}$ & $\mathbf{0 . 0 0 7 0}$ & 0.3750 & - \\
\hline
\end{tabular}

Statistically significant differences are +marked in bold. LLC, Lewis lung carcinoma; BGs, bacterial ghosts; B.s.B-7025, B. subtilis $\mathrm{B}-7025$ $70 \mathrm{kDa}$.

development of pulmonary metastatic foci in $100 \%$ of the analysed control and LLC samples. In contrast, only 33\% of the analysed lung samples of both the LLC+B.s.B-7025 and LLC+BGs groups displayed signs of metastasis. Fig. 3 shows representative lung slices presenting various spreads of metastasis in the investigated groups. The mean size of the metastatic tumours in the LLC group was $0.452 \pm 0.3 \mathrm{~mm}^{2}$, whereas in the LLC+B.s.B-7025 group it was $0.016 \pm 0.013 \mathrm{~mm}^{2}$ and in the LLC+BGs group only $0.006 \pm 0.0001 \mathrm{~mm}^{2}$. Mann-Whitney U-test confirmed that the LLC+BGs metastasis size was significantly smaller then that of the LLC group ( $\mathrm{P}=0.019)$, unlike the $\mathrm{LLC}+B$.s. $\mathrm{B}-7025$ group $(\mathrm{P}=0.514)$.

Flow cytometry. Whole blood samples were analysed for CD8a surface antigen expression at two different time-points (before the vaccination and at the end of the study). Representative graphs are shown in Fig. 4. Summarised results are presented in Fig. 5. The number of cells expressing CD8a remained at the same level before and after vaccination in both the control and LLC + B.s.B-7025 groups. On the other hand, compared to the measurement taken before the vaccinations, the mice treated with non-adjuvanted LLC lysate had a significantly lower CD8a count in the blood at the end of the study $(\mathrm{P}<0.001)$, whereas the mice in the LLC+BGs group had a significantly higher $\mathrm{CD} \mathrm{a}^{+}$cell count at the end of the study $(\mathrm{P}=0.019)$. Notably, at the end of the study, CD8a expression in the LLC+BGs group was significantly higher than that noted in the control $(\mathrm{p}=0.047), \mathrm{LLC}+$ B.s. $\mathrm{B}-7025(\mathrm{P}=0.026)$ and LLC $(\mathrm{P}=0.002)$ groups. Mice treated with $\mathrm{LLC}+$ B.s. $\mathrm{B}-7025$ vaccine had a higher $\mathrm{CD} 8 \mathrm{a}^{+}$cell count than that noted in the mice

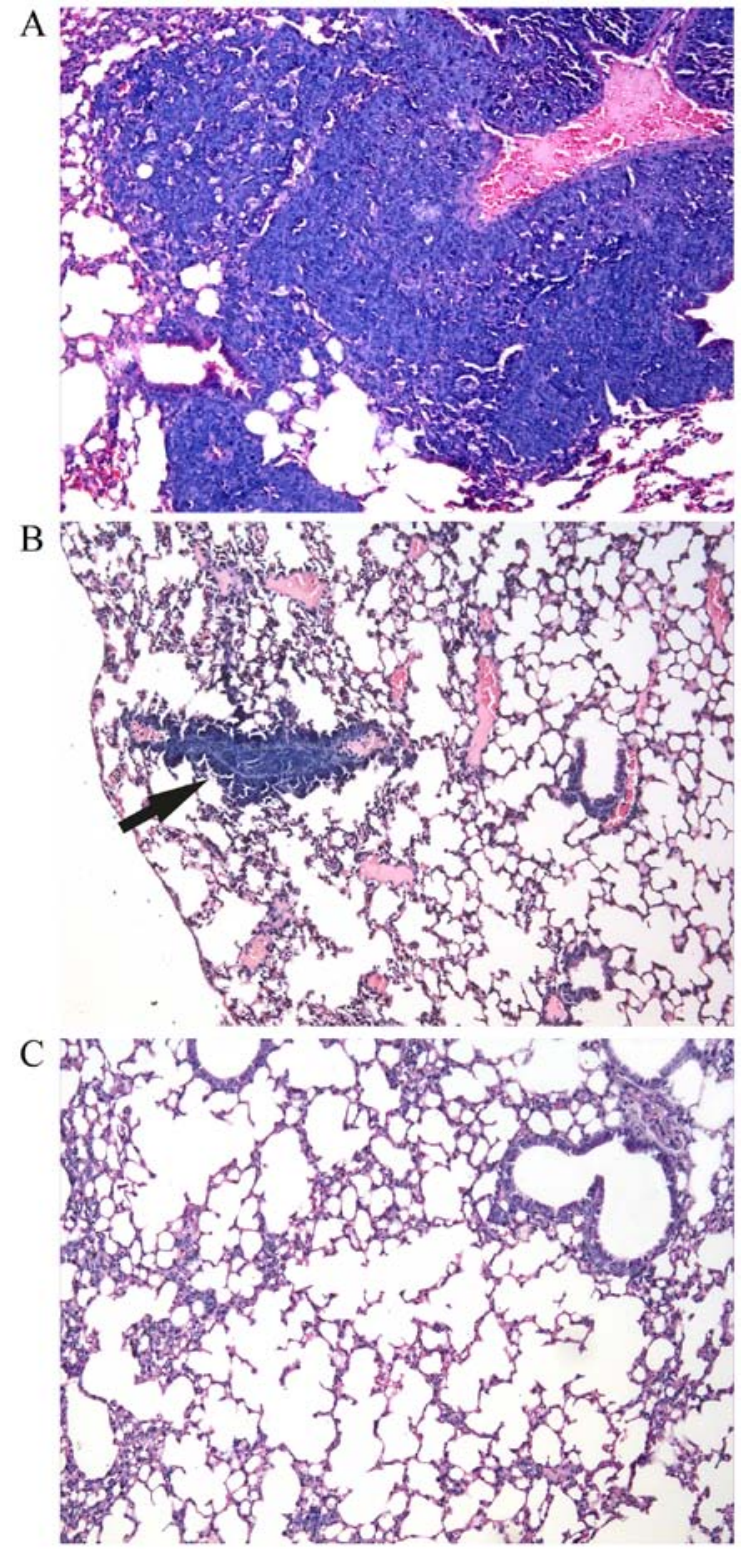

Figure 3. Histochemical staining of lung samples from the dead C57BL/6 mice. Staining, hematoxylin and eosin. Magnification, x100. (A) Metastatic focus fills the entire field of view. (B) Metastatic focus is indicated by arrows. (C) Clean lung slice with no sign of metastasis.

treated with the LLC lysate alone $(\mathrm{P}<0.001)$, but not statistically different from the control group $(\mathrm{P}=0.782)$ (Fig. 5). 

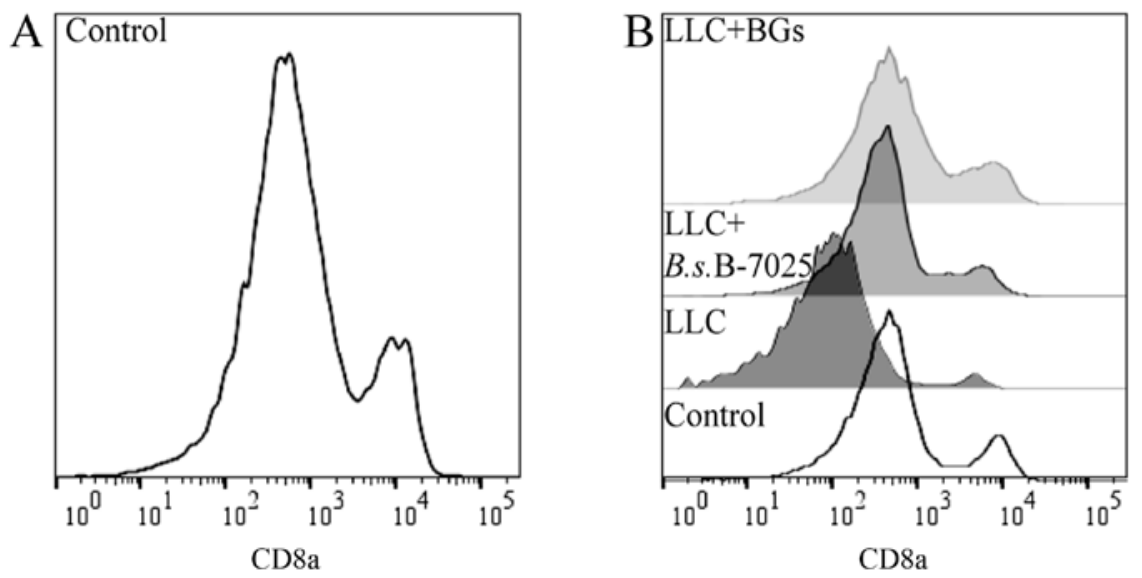

Figure 4. Half-offset histograms of the CD8a signal registered on a flow cytometer before vaccination (A) and at the end of the study (B). Control (white) and the three therapeutic groups are displayed (shades of grey).

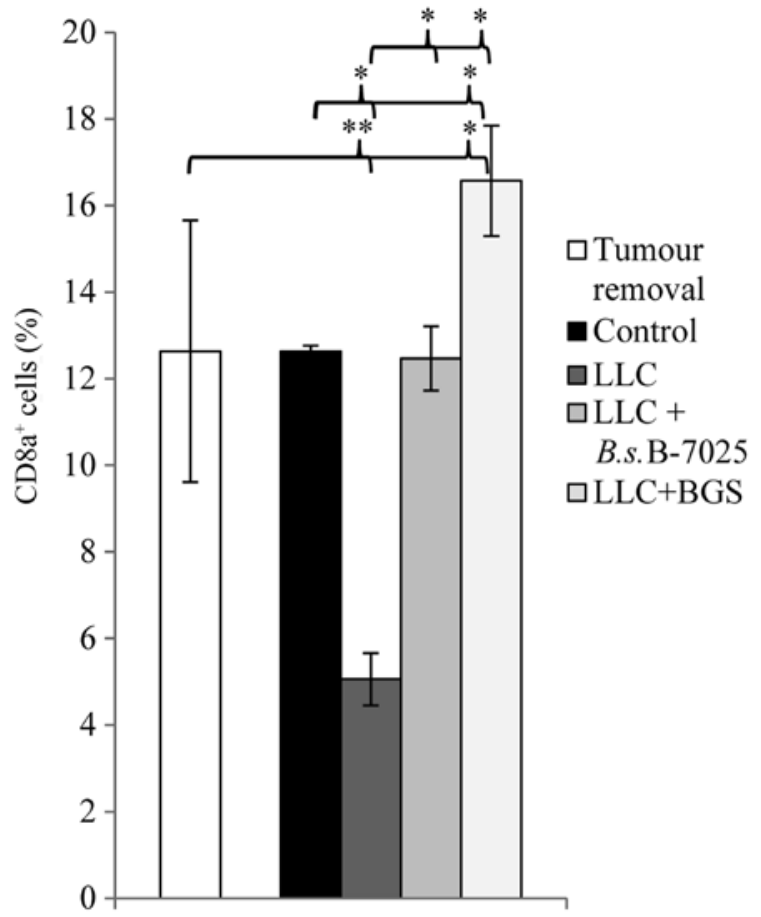

Figure 5. Data represent the mean $\pm \mathrm{SD}$ of three independent measurements performed using murine lymphocytes obtained before the vaccination treatment (white) and at the end of the study in the various treatment groups (shades of grey). See Fig. 1 for sampling details. ${ }^{*} \mathrm{P}<0.05$ and ${ }^{* * *} \mathrm{P}<0.01$.

\section{Discussion}

In the present study, C57BL/6 mice, inoculated with metastasizing LLC cells, received adjuvant treatment with therapeutic vaccines following surgical removal of primary tumour. The proposed approach is clinically relevant, due to the fact that management of micrometastatic or unresectable metastatic disease in patients after primary tumour resection is still a challenge in modern oncology $(51,52)$. Primary tumour removal was introduced to focus more on metastasis inhibition rather than on tumour growth inhibition. Lungs were investigated for metastatic foci due to the known affinity of LLC cells, which spread preferentially to lung tissue (49). Syngeneic
LLC lysate was used as a vaccine (source of tumour antigens for immunization). To counter the potential immunosuppressive characteristics of the tumour lysate (17) and augment the evolving antitumour immune responses, two distinct bacterial-based adjuvants were used with the therapeutic vaccination. These adjuvants included either $B$. subtilis B-7025 $70 \mathrm{kDa}$ protein isolates or bacterial ghost generated from probiotic E. coli Nissle 1917. Whole bacterial-based adjuvant systems gained attention in oncology with the introduction of bacillus Calmette-Guérin immunotherapy for the treatment of non-muscle invasive bladder cancer (53). Currently this type of cancer immunotherapy was further improved by manipulating bacteria and loading them with tumour antigens in order to ensure tumour antigen specificity of the elicited immune responses. Such innovative approaches include live, attenuated Listeria monocytogenes bacteria consisting of gene deletions to diminish their pathogenicity and engineered to express tumour antigens (54). Recent data have shown that immunotherapy with mesothelin-expressing, live, attenuated L. monocytogenes CRS-207 plus chemotherapy demonstrate encouraging clinical activity in patients with malignant pleural mesothelioma (55). Our investigated BG platform also emerges as a very promising immunotherapeutic tool of this kind. It may even be safer, since it exploits completely non-living and intact bacterial envelopes rather than attenuated or killed, but metabolically active, bacteria.

The study results showed that treatment of tumourbearing mice with LLC+BGs or LLC+B.s.B-7025 prevented the formation of lung metastasis in $67 \%$ of the mice, while no protective effect was detected in the mice treated with LLC lysate-alone and in mice without treatment (control group) (Fig. 3). Although the median overall survival of the mice treated either with LLC+BGs and LLC+B.s.B-7025 was the same ( 84 days) and increased compared with the controls (53.5 days), only the treatment with LLC+BGs led to a statistically significant median overall survival (Fig. 2). Moreover, the survival rate of the mice from the LLC+BGs treatment group at day 84 was significantly increased when compared with the survival rate of mice from the LLC+B.s.B-7025 treatment group ( 80 vs. $60 \%$ ). Mice treated with non-adjuvant LLC lysate had a significantly shorter survival than those treated with LLC+BGs or LLC+B.s.B-7025 
Cytotoxic lymphocytes are thought to be the key factor in successful anticancer immune response (56). Smaller metastatic foci found in lung samples (Fig. 3) can explain why the LLC+BGs vaccine achieved a better survival rate than LLC+B.s.B-7025. Smaller metastatic foci found in lung samples of the mice treated with the LLC+BGs vaccine (compared to lung samples of mice from other treatment groups) along with improved median overall survival of mice might be associated with the detected elevated numbers of circulating CD8 $\mathrm{a}^{+} \mathrm{T}$ cells at the end of the study. Subcutaneous administration of vaccine made of LLC+BGs elicited a significantly higher number of circulating CD8 $\mathrm{a}^{+} \mathrm{T}$ cells in the tumour-bearing mice compared to the numbers of total circulating $\mathrm{CD} \mathrm{a}^{+} \mathrm{T}$ cells detected in blood samples obtained from the non-treated mice as well as from mice treated with the vaccine made of LLC $+B$.s.B-7025 and LLC alone. Moreover, only mice treated with LLC+BGs vaccine, compared to other treatment groups, had at the end of the study a significantly higher number of circulating $\mathrm{CD} \mathrm{a}^{+} \mathrm{T}$ cells than before the vaccination onset (Fig. 5). Noteworthy, the standard deviation of $\mathrm{CD}_{8} \mathrm{a}^{+}$cells in the LLC+BGs group was three times smaller when measured in the surviving vs. the dead mice at the end of the study (data not shown). This fact implies that the surviving mice can be characterised by a successful CTL mobilisation. This is in line with already published data, where authors also detected higher CD8a levels only in responder mice, treated with a TCL-based vaccine (57).

Notably, the level of blood CD8a ${ }^{+} \mathrm{T}$ cells was significantly decreased in the mice treated with the non-adjuvant-modified LLC lysate compared with the controls and mice treated with adjuvanted LLC lysates (Fig. 5). In addition, mice treated with non-adjuvanted LLC lysate showed the lowest survival rate of only $25 \%$ compared with 80,60 and $40 \%$ in the LLC+BGs, LLC $+B . s . \mathrm{B}-7025$ and control groups, respectively. We assume that various immunosuppressants present in the tumour lysate were responsible for the decrease in $\mathrm{CD} 8 \mathrm{a}^{+} \mathrm{T}$ cell population as a result of predominant cancer-associated immunosuppressive environment. However, coupling of LCC lysate vaccine preparations with strong immunostimulators, especially with BGs, can modulate the character of LCC lysate from immunosuppressive to immunostimulatory by improving both the recognition and presentation of tumour-associated neo-antigens by professional antigen-presenting cells capable then of activating and (re)stimulating effector immune competent cells. Indeed it has been previously shown that the generation of tolerogenic DCs was induced by culturing immature DCs from healthy donors with the plasma of pancreatic cancer patients (58) or supernatants of various tumour cell lines $(14,59)$.

In the light of this preliminary study, BGs emerge as a novel adjuvant and antigen delivery platform for TCL-based therapeutic cancer vaccination. This straightforward and potentially clinically effective immunotherapeutical approach requires more extensive pre-clinical investigation and warrants consideration outside the animal models.

\section{Acknowledgements}

This study was supported by the Lithuanian Research Council project 'Immunomodulating properties of bacteriophage derived dsRNA of different size and their use as vaccine adjuvants' no. TAP-LLT-15-028.

\section{References}

1. Vesely MD and Schreiber RD: Cancer immunoediting: Antigens, mechanisms, and implications to cancer immunotherapy. Ann NY Acad Sci 1284: 1-5, 2013.

2. Zitvogel L, Tesniere A and Kroemer G: Cancer despite immunosurveillance: Immunoselection and immunosubversion. Nat Rev Immunol 6: 715-727, 2006.

3. Bose A, Chakraborty T, Chakraborty K, Pal S and Baral R: Dysregulation in immune functions is reflected in tumor cell cytotoxicity by peripheral blood mononuclear cells from head and neck squamous cell carcinoma patients. Cancer Immun 8: $10,2008$.

4. Noguchi A, Kaneko T, Naitoh K, Saito M, Iwai K, Maekawa R, Kamigaki $\mathrm{T}$ and Goto S: Impaired and imbalanced cellular immunological status assessed in advanced cancer patients and restoration of the T cell immune status by adoptive T-cell immunotherapy. Int Immunopharmacol 18: 90-97, 2014.

5. Galluzzi L, Vacchelli E, Bravo-San Pedro JM, Buqué A, Senovilla L, Baracco EE, Bloy N, Castoldi F, Abastado JP, Agostinis P, et al: Classification of current anticancer immunotherapies. Oncotarget 5: 12472-12508, 2014.

6. Guo C, Manjili MH, Subjeck JR, Sarkar D, Fisher PB and Wang XY: Therapeutic cancer vaccines: Past, present, and future. Adv Cancer Res 119: 421-475, 2013.

7. Butterfield LH: Cancer vaccines. BMJ 350: h988, 2015.

8. Palucka $\mathrm{K}$ and Banchereau J: Cancer immunotherapy via dendritic cells. Nat Rev Cancer 12: 265-277, 2012.

9. Schijns V, Tartour E, Michalek J, Stathopoulos A, Dobrovolskienė NT and Strioga MM: Immune adjuvants as critical guides directing immunity triggered by therapeutic cancer vaccines. Cytotherapy 16: 427-439, 2014.

10. Chiang CL, Coukos G and Kandalaft LE: Whole tumor antigen caccines: Where Are We? Vaccines (Basel) 3: 344-372, 2015.

11. Gerlinger M, Rowan AJ, Horswell S, Larkin J, Endesfelder D, Gronroos E, Martinez P, Matthews N, Stewart A, Tarpey P, et al: Intratumor heterogeneity and branched evolution revealed by multiregion sequencing. N Engl J Med 366: 883-892, 2012.

12. Srivatsan S, Patel JM, Bozeman EN, Imasuen IE, He S, Daniels D and Selvaraj P: Allogeneic tumor cell vaccines: The promise and limitations in clinical trials. Hum Vaccin Immunother 10: 52-63, 2014.

13. Schnurr M, Galambos P, Scholz C, Then F, Dauer M, Endres S and Eigler A: Tumor cell lysate-pulsed human dendritic cells induce a T-cell response against pancreatic carcinoma cells: An in vitro model for the assessment of tumor vaccines. Cancer Res 61: 6445-6450, 2001.

14. Kuang DM, Zhao Q, Xu J, Yun JP, Wu C and Zheng L: Tumor-educated tolerogenic dendritic cells induce CD3epsilon down-regulation and apoptosis of $\mathrm{T}$ cells through oxygendependent pathways. J Immunol 181: 3089-3098, 2008.

15. Li H, Zhu H, Xu CJ and Yuan J: Cleavage of BID by caspase 8 mediates the mitochondrial damage in the Fas pathway of apoptosis. Cell 94: 491-501, 1998.

16. Schuster N and Krieglstein K: Mechanisms of TGF-beta-mediated apoptosis. Cell Tissue Res 307: 1-14, 2002.

17. Dong B, Dai G, Xu L, Zhang Y, Ling L, Sun L and Lv J: Tumor cell lysate induces the immunosuppression and apoptosis of mouse immunocytes. Mol Med Rep 10: 2827-2834, 2014.

18. Strioga MM, Felzmann T, Powell DJ Jr, Ostapenko V, Dobrovolskiene NT, Matuskova M, Michalek J and Schijns VE: Therapeutic dendritic cell-based cancer vaccines: The state of the art. Crit Rev Immunol 33: 489-547, 2013.

19. Beck B, Dörfel D, Lichtenegger FS, Geiger C, Lindner L, Merk M, Schendel DJ and Subklewe M: Effects of TLR agonists on maturation and function of 3-day dendritic cells from AML patients in complete remission. J Transl Med 9: 151, 2011.

20. Kawahara M and Takaku H: Intradermal immunization with combined baculovirus and tumor cell lysate induces effective antitumor immunity in mice. Int J Oncol 43: 2023-2030, 2013.

21. Temizoz B, Kuroda E and Ishii KJ: Vaccine adjuvants as potential cancer immunotherapeutics. Int Immunol 28: 329-338, 2016.

22. Kurooka M and Kaneda Y: Inactivated Sendai virus particles eradicate tumors by inducing immune responses through blocking regulatory T cells. Cancer Res 67: 227-236, 2007. 
23. Bungener L, Huckriede A, Wilschut J and Daemen T: Delivery of protein antigens to the immune system by fusion-active virosomes: A comparison with liposomes and ISCOMs. Biosci Rep 22: 323-338, 2002

24. Liu H, Tu Z, Feng F, Shi H, Chen K and Xu X: Virosome, a hybrid vehicle for efficient and safe drug delivery and its emerging application in cancer treatment. Acta Pharm 65: 105-116, 2015.

25. Wiedermann U, Wiltschke C, Jasinska J, Kundi M, Zurbriggen R, Garner-Spitzer E, Bartsch R, Steger G, Pehamberger H, Scheiner O, et al: A virosomal formulated Her-2/neu multipeptide vaccine induces Her-2/neu-specific immune responses in patients with metastatic breast cancer: A phase I study. Breast Cancer Res Treat 119: 673-683, 2010.

26. Witte A, Wanner G, Sulzner M and Lubitz W: Dynamics of PhiX174 protein E-mediated lysis of Escherichia coli. Arch Microbiol 157: 381-388, 1992.

27. Henrich B, Lubitz W and Plapp R: Lysis of Escherichia coli by induction of cloned phi X174 genes. Mol Gen Genet 185 : 493-497, 1982

28. Montanaro J, Inic-Kanada A, Ladurner A, Stein E, Belij S, Bintner N, Schlacher S, Schuerer N, Mayr UB, Lubitz W, et al Escherichia coli Nissle 1917 bacterial ghosts retain crucial surface properties and express chlamydial antigen: An imaging study of a delivery system for the ocular surface. Drug Des Devel Ther 9: 3741-3754, 2015.

29. Eko FO, Mayr UB, Attridge SR and Lubitz W: Characterization and immunogenicity of Vibrio cholerae ghosts expressing toxin-coregulated pili. J Biotechnol 83: 115-123, 2000.

30. Kudela P, Koller VJ and Lubitz W: Bacterial ghosts (BGs) - advanced antigen and drug delivery system. Vaccine 28: $5760-5767,2010$

31. Zhu W, Yang G, Zhang Y, Yuan J and An L: Generation of biotechnology-derived Flavobacterium columnare ghosts by PhiX174 gene E-mediated inactivation and the potential as vaccine candidates against infection in grass carp. J Biomed Biotechnol 2012: 760730, 2012.

32. Cai K, Zhang Y, Yang B and Chen S: Yersinia enterocolitica ghost with msbB mutation provides protection and reduces proinflammatory cytokines in mice. Vaccine 31: 334-340, 2013.

33. Riedmann EM, Kyd JM, Cripps AW and Lubitz W: Bacterial ghosts as adjuvant particles. Expert Rev Vaccines 6: 241-253, 2007.

34. Muhammad A, Champeimont J, Mayr UB, Lubitz W and Kudela P: Bacterial ghosts as carriers of protein subunit and DNA-encoded antigens for vaccine applications. Expert Rev Vaccines 11: 97-116, 2012.

35. Podgorskiı VS, Kovalenko EA, Get'man EI, Potebnia GP and Tanasienko OA: Lectin activity of antitumor substances synthesized by Bacillus subtilis B-7025 Mikrobiol Z 64: 10-17, 2002 (In Russian).

36. Tanasienko OA, Cheremshenko NL, Titova GP, Potebnya MG, Gavrilenko MM, Nagorna SS and Kovalenko NK: Elevation of the efficacy of antitumor vaccine prepared on the base of lectines from $B$. subtilis B-7025 upon its combined application with probiotics in vivo. Exp Oncol 27: 336-338, 2005.

37. Potebnia HP, Safronova LA, Cheremshenko NL, Lisovenko HS, Sorokulova IB, Prykhod'ko VO, Trokhymenko NV, TanasiienkoOA and Bombin AV: Influence of probiotic subalin on efficiency of antitumor vaccine Mikrobiol Zh 68: 51-58, 2006 (In Ukrainian).

38. Potebnya GP,Lisovenko GS, Trokhimenko NV, Cheremshenko NL, Didenko GV, Reder AS and Andronati SA: Elevation of efficacy of cancer vaccine combined with interferon and inducer of endogeneous interferon synthesis amixin. Exp Oncol 30: 319-323, 2008

39. Tanasienko OA, Rudyk MP, Pozur VV and Potebnya GP: Influence of bacterial lectins on some reactions of nonspecific immunity in sarcoma 37 transplanted mice. Exp Oncol 32: 254-257, 2010

40. Potebnya G, Cheremshenko N, Lisovenko G, Voyekova I, Bazas' V, Todor I and Chekhun V: Antitumor efficacy of autovaccines prepared from chemoresistant tumor cells with the use of lectin OF B. subtilis B-7025. Exp Oncol 29: 277-280, 2007.

41. Potebnya GP, Kudryavets YY, Lisovenko GS, Cheremshenko NL, Voeykova IM, Trokhimenko NV, Symchich TV and Evstrateyva LM: Experimental study of the efficacy of combined use of cancer vaccine and interferon. Exp Oncol 29: 102-105, 2007.
42. Potebnya GP, Voeykova IM, Lisovenko GS, Cheremshenko NL, Todor IM, Yudina OY, Kovtonyuk OV and Chekhun VF: Antitumor and antimetastatic activities of vaccine prepared from cisplatin-resistant lewis lung carcinoma. Exp Oncol 31: 226-230, 2009.

43. Xu X, Huang Q, Mao Y, Cui Z, Li Y, Huang Y, Rajput IR, Yu D and Li W: Immunomodulatory effects of Bacillus subtilis (natto) B4 spores on murine macrophages. Microbiol Immunol 56: 817-824, 2012

44. Lee SW,Park HJ,Park SH,Kim N and Hong S: Immunomodulatory effect of poly- $\gamma$-glutamic acid derived from Bacillus subtilis on natural killer dendritic cells. Biochem Biophys Res Commun 443: 413-421, 2014

45. Langemann T, Koller VJ, Muhammad A, Kudela P, Mayr UB and Lubitz W: The Bacterial ghost platform system: Production and applications. Bioeng Bugs 1: 326-336, 2010.

46. Didenko GV, Dvorschenko OS, Lisovenko GS, Kovalenko NG, Potebnya GP, Kikot VV, Pozur VK and Golub AA: The modification of cancer vaccine prepared on the base of metabolic products of $B$. subtilis 7025 with the use of sorbents and automacrophages. Exp Oncol 25: 116-118, 2003.

47. Didenko GV, Kuzmenko AP, Shpak EG, Tawrovska IA, Nadirashvili NA, Blum IO and Potebnya GP: Optimization of the methods of isolation, electrophoretic characterization, and antitumor efficacy of cytotoxic metabolites from the culture filtrate Bacillus subtilis B-7025. Dop. NAS Ukraine 7: 185-190, 2012.

48. Lowry OH, Rosebrough NJ, Farr AL and Randall RJ: Protein measurement with the Folin phenol reagent. J Biol Chem 193: 265-275, 1951.

49. Niu PG, Zhang YX, Shi DH, Liu Y, Chen YY and Deng J: Cardamonin inhibits metastasis of Lewis lung carcinoma cells by decreasing mTOR activity. PLoS One 10: e0127778, 2015.

50. Schneider CA, Rasband WS and Eliceiri KW: NIH Image to ImageJ: 25 years of image analysis. Nat Methods 9: 671-675, 2012 .

51. Schirrmacher V, Fournier P and Schlag P: Autologous tumor cell vaccines for post-operative active-specific immunotherapy of colorectal carcinoma: Long-term patient survival and mechanism of function. Expert Rev Vaccines 13: 117-130, 2014.

52. Laufer I, Iorgulescu JB, Chapman T, Lis E, Shi W, Zhang Z, Cox BW, Yamada Y and Bilsky MH: Local disease control for spinal metastases following 'separation surgery' and adjuvant hypofractionated or high-dose single-fraction stereotactic radiosurgery: Outcome analysis in 186 patients. J Neurosurg Spine 18: 207-214, 2013.

53. Brandau S and Suttmann H: Thirty years of BCG immunotherapy for non-muscle invasive bladder cancer: A success story with room for improvement. Biomed Pharmacother 61: 299-305, 2007.

54. Rothman J and Paterson Y: Live-attenuated Listeria-based immunotherapy. Expert Rev Vaccines 12: 493-504, 2013.

55. Jahan T, Hassan R, Alley E, Kindler H, Antonia S, Whiting C, Coussens L, Murphy AL, Thomas A and Brockstedt DG: 208O_PR: CRS-207 with chemotherapy (chemo) in malignant pleural mesothelioma (MPM): results from a phase $1 \mathrm{~b}$ trial. J Thorac Oncol 11 (4 Suppl): S156, 2016.

56. Becht E, Giraldo NA, Dieu-Nosjean MC, Sautès-Fridman C and Fridman WH: Cancer immune contexture and immunotherapy. Curr Opin Immunol 39: 7-13, 2016.

57. Kawahara M and Takaku H: A tumor lysate is an effective vaccine antigen for the stimulation of CD4(+) T-cell function and subsequent induction of antitumor immunity mediated by CD8(+) T cells. Cancer Biol Ther 16: 1616-1625, 2015.

58. Tjomsland V, Spångeus A, Sandström P, Borch K, Messmer D and Larsson M: Semi mature blood dendritic cells exist in patients with ductal pancreatic adenocarcinoma owing to inflammatory factors released from the tumor. PLoS One 5: e13441, 2010.

59. Kúdela P, Schwarczová Z, Sedlák J and Bizik J: Conditioned medium from HeLa cells enhances motility of human monocytederived dendritic cells but abrogates their maturation and endocytic activity. Neoplasma 48: 382-388, 2001. 